\title{
Malaria: A Cause of Anemia and Its Effect on Pregnancy
}

\author{
${ }^{1}$ Richa Saxena, ${ }^{2}$ Arun Bhatia, ${ }^{3}$ Kanav Midha, ${ }^{4}$ Mampi Debnath, ${ }^{5}$ Prabhjot Kaur
}

\begin{abstract}
Malaria is one of the major health problems in the world. It remains an important cause of very high human morbidity and mortality, especially, among children and pregnant women. It results from the infection of parasites belonging to the genus Plasmodium. Plasmodium falciparum and Plasmodium vivax are the major pathogens responsible for causing human malaria. Approximately $75 \%$ of cases are caused by $P$. falciparum and associated with the mortality rate of approximately 0.5 to $1.0 \%$. Both $P$. falciparum and $P$. vivax induce anemia during their erythrocytic stages of infection. Most of the malarial infections are related to some degree of anemia, the severity of which depends upon patient-specific characteristics (e.g., age, innate and acquired resistance, comorbid features, etc.) as well as parasite-specific characteristics (e.g., species, adhesive, and drug-resistant phenotype, etc.). Malarial anemia encompasses reduced production of erythrocytes as well as increased removal of circulating erythrocytes in the bone marrow. Susceptibility to severe malarial anemia is associated with the polymorphisms of the cytokines, which are likely to function by perturbing erythropoiesis. This article reviews the epidemiology, pathophysiology, clinical features, treatment, and various complications occurring due to malarial anemia. The second part of this article also focuses on the effect of malaria during pregnancy. Some significant effects of malaria during pregnancy include spontaneous abortion, preterm delivery, low birthweight, stillbirth, congenital infection, and maternal death.
\end{abstract}

Keywords: Anemia, Black water anemia, Bone marrow, Cytokine, Dyserythropoiesis, Erythropoiesis, Hemolysis, Malaria, Plasmodium falciparum, Plasmodium vivax.

How to cite this article: Saxena R, BhatiaA, Midha K, Debnath M, Kaur P. Malaria: A Cause of Anemia and Its Effect on Pregnancy. World J Anemia. 2017;1(2):51-62.

Source of support: Nil

Conflict of interest: None

\footnotetext{
${ }^{1}$ Head, ${ }^{2}$ Surgeon, ${ }^{3-5}$ Postgraduate

${ }^{1}$ Jaypee Brothers Medical Publishers (P) Ltd., New Delhi, India

${ }^{2}$ Department of Dentistry, Arun Dental Clinic, Faridabad, Haryana India

${ }^{3}$ Department of Pharmaceutical Sciences, Chitkara University Chandigarh, India

${ }^{4}$ Department of Microbiology and Biotechnology Centre Maharaja Sayajirao University of Baroda, Vadodara, India

${ }^{5}$ Department of Nutrition, University of Delhi, New Delhi, India

Corresponding Author: Richa Saxena, Head, Jaypee Brothers Medical Publishers (P) Ltd., New Delhi, India, Phone: +919971234834 e-mail: synapse94@hotmail.com
}

\section{INTRODUCTION}

Malaria remains a major world health problem even today. Despite the advent of various new control measures and diagnostic methodologies, there has been only $18 \%$ decline in the number of malaria cases and nearly $50 \%$ decline in the mortality rate due to malaria. According to a study conducted globally, the death toll remained very high between the years 2000 and 2015. Hence, malaria remained a major assassin of children, especially, in the area of Sub-Saharan Africa, where a child dies every 2 minutes due to malaria. ${ }^{1}$ Malaria is an infective disease resulting from infection of parasites belonging to the genus Plasmodium. Plasmodium falciparum and Plasmodium vivax cause the major human malaria. Out of these, P. falciparum has been the more virulent one.

Malaria is one of the important causes of anemia. However, malaria as the cause of anemia has been incompletely understood and anemia resulting from malaria has been a significant cause of morbidity and mortality. ${ }^{2-5}$ It has been observed that P. falciparum and P. vivax induce anemia during the erythrocytic stages of malarial infection. Anemia caused due to malaria seems to be a multifactorial disease and, for this reason, the etiological basis for it has also been incompletely defined. Etiology for malarial anemia in malaria-endemic areas includes various overlapping features, such as lysis of infected or uninfected red blood cells (RBCs), ${ }^{6}$ splenic sequestration of RBCs, ${ }^{7}$ dyserythropoiesis and bone marrow suppression, ${ }^{8}$ infectious diseases, and the chronic transmission of malaria. Though the same features exist with P. vivax infection, this infection has been more difficult to eradicate in comparison with P. falciparum due to its particular biological characteristics. ${ }^{9-17}$

\section{EPIDEMIOLOGY}

\section{Malarial Parasite}

Malaria parasites belong to the genus Plasmodium. There exist more than 100 species of the genus Plasmodium. Until now, only five species of the genus Plasmodium have been recognized to infect human species. The five types of Plasmodium found to infect human species are as follows:

1. Plasmodium falciparum: It is found worldwide in the tropical as well as subtropical areas, especially in Africa where this species predominates. Malaria caused by P. falciparum is likely to be associated with greater morbidity and mortality in comparison with the nonfalciparum infections. 
2. Plasmodium ovale: It is found mostly in the African area (especially West Africa) and the islands of the western Pacific.

3. Plasmodium malariae: This is the species, i.e., found worldwide, and is the only human malaria parasite species that has a quartan cycle.

4. Plasmodium vivax: It is found mostly in Asia, Latin America, and in some parts of Africa. Due to the high population density, especially in Asia, it is probably the most prevalent human malarial parasite.

5. Plasmodium knowlesi: It is found throughout Southeast Asia as a natural pathogen of long-tailed and pigtailed macaques.

Malarial parasite is transmitted by the bite of a sporozoite-bearing female anopheline mosquito. Life cycle of malarial parasite is illustrated in Figure 1. Following the mosquito bite, initially, there is a period of pre-erythrocytic phase in the liver. Following this, the erythrocytic stage of infection occurs, which causes disease manifestations. During this stage, invasion of the erythrocyte by the parasite results in the consumption of hemoglobin and alteration of the red cell membrane. This causes $P$. falciparum-infected erythrocytes to cytoadhere inside the small blood vessels of brain, kidneys, and other affected organs. There also occurs rosetting, which can be defined as the adherence of uninfected RBCs. Both of these processes, cytoadherence and rosetting, interfere with microcirculatory flow and metabolism of vital organs.

Besides the above-described processes, the hallmark of falciparum malaria in pregnancy is the sequestration of parasites in the placenta. Sequestered parasites escape host defense mechanisms, such as splenic processing and filtration. Sequestration is not known to occur in the benign malarias due to $P$. vivax, P. ovale, and P. malariae.

\section{PREVALENCE}

Malarial infection has been considered to be one of the most prevalent health problems in terms of morbidity as well as mortality, and it has been found to result in more than 200 million cases all over the world. Also, it is known to be the cause of 655,000 deaths every year worldwide. $^{18}$

A total of around 216 million malaria cases were reported in the year of 2010. Africa claims to have $81 \%$ of these cases. This was followed by Southeast Asia with $13 \%$ and the Mediterranean region was the last with 5\% of cases.

The major proportion of population that gets exposed to the malaria parasites has witnessed a decline during the last century. From the year 1900 to the year 2010, the population at risk of getting malarial infection has increased from 0.8 to 3.3 billion. This seems to have occurred due to an increase in the population of the malaria-endemic regions. ${ }^{18,19}$

In a given population, the proportion of individuals with splenomegaly was the first ever recorded method used to assess malaria endemic data in the survey conducted in 1848 in India. In this survey, the dimension of the spleen was measured in the specific age group. According to splenomegaly prevalence rates in 2- to 9-year-old children, four different endemic areas were identified: (1) Holoendemic areas: individuals with splenomegaly above $75 \%$; (2) hyperendemic areas: individuals with splenomegaly between $51 \%$ and $75 \%$; mesoendemic areas: individuals with splenomegaly between

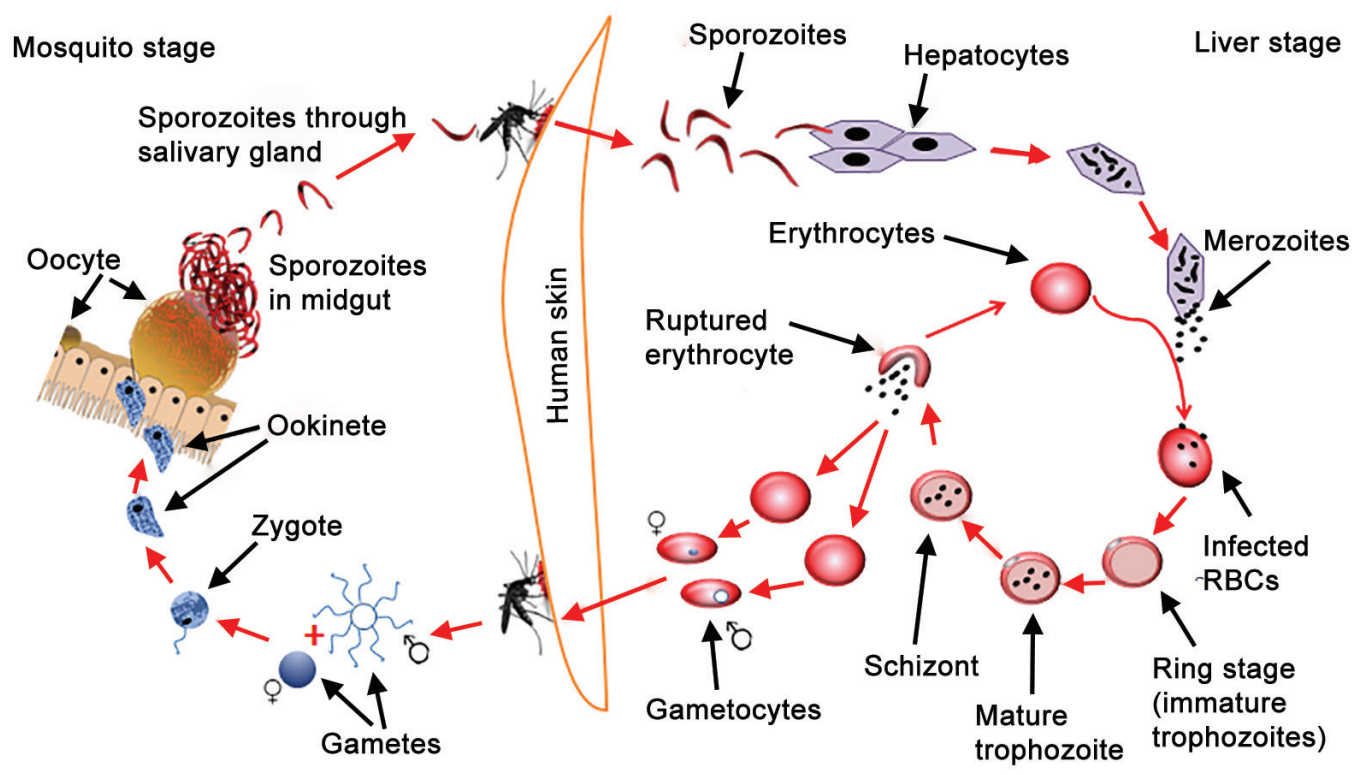

Fig. 1: Life cycle of malarial parasite 


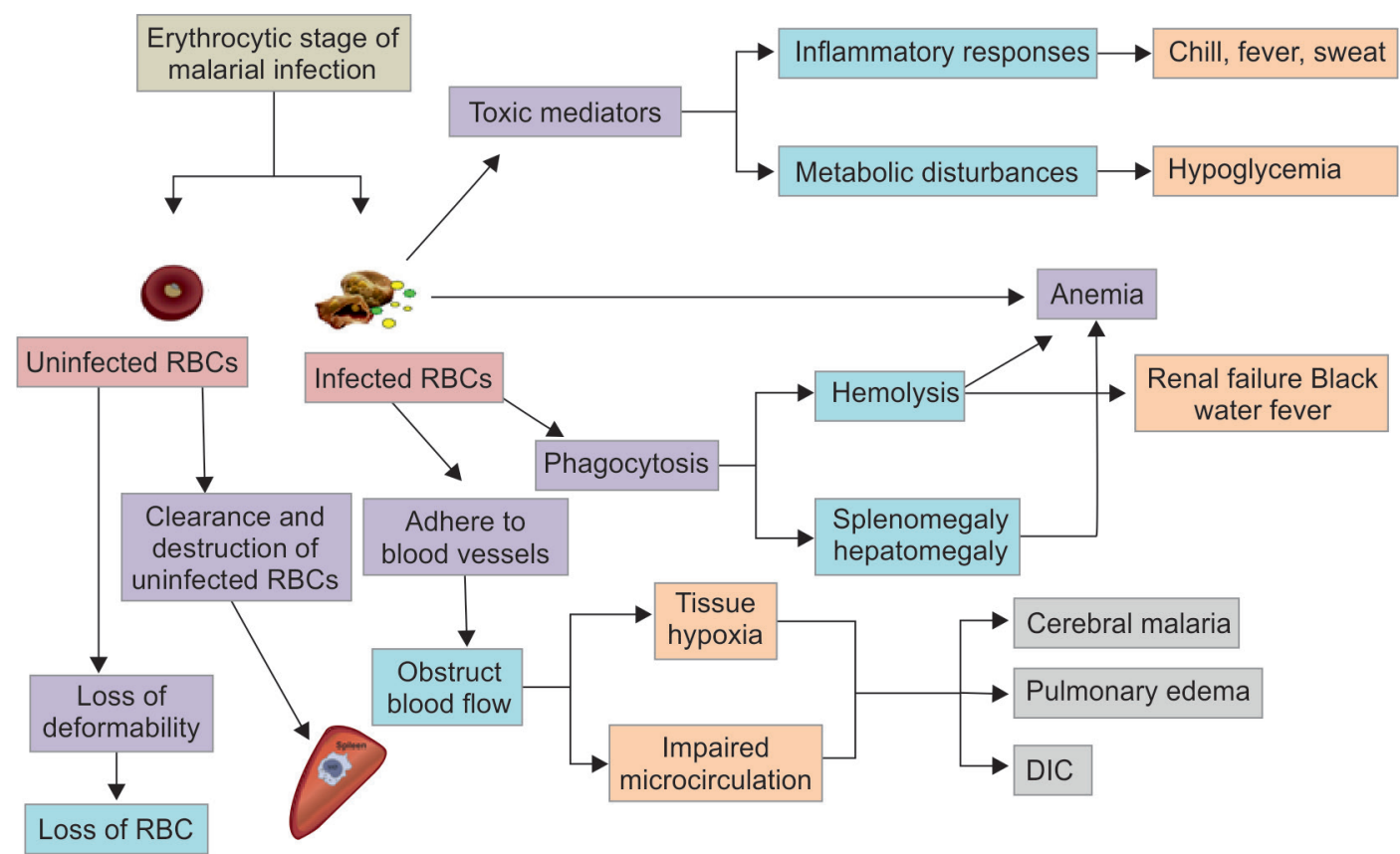

Fig. 2: Pathogenesis of malarial infection. DIC: Disseminated intravascular coagulation

50 and $11 \%$; and hypoendemic areas: individuals with splenomegaly below $11 \%{ }^{20}$

\section{PATHOPHYSIOLOGY}

Pathogenesis of malarial infection is described in Figure 2. Malarial infection is a common cause of anemia, especially among children and pregnant women. The etiology of anemia due to malaria is often multifactorial and illustrated in Figure 3.

\section{Hemolysis of Parasitized RBCs}

Human malarial parasite enters the human body as Plasmodium sporozoites after an infected anopheline mosquito bite. While biting, the sporozoites in the mosquito travel from its salivary glands to the host's liver, where they invade hepatocytes. The sporozoite cells divide many times and, due to this, mature tissue schizonts develop. Each of the hepatocyte now contains many thousands of merozoites. This pre-erythrocytic stage is asymptomatic. After this exoerythrocytic stage, the liver schizonts rupture after few days, which now release many thousands of merozoites into the bloodstream, and hereby the merozoites invade the erythrocytes.

The human malarial species mostly invades the RBCs. $P$. vivax has a very special affinity for $R B C$ s that have developed from the bone marrow and are only 14 days old. The P. falciparum has lower affinity for young RBCs and thus, has significant ability to infect the older cells. The blood stages of malarial infection are responsible for most of the symptoms and pathologies, which are associated with malaria.
The infected erythrocytes are host to the replicating malarial parasites for 48 hours before bursting, thus releasing the daughter merozoites. Parasitemia caused by $P$. vivax is symptomatically milder than is the one caused by $P$. falciparum ${ }^{20}$ The merozoites thus produced after being released following rupture of the infected red cell get attached to the surface of the other uninfected red cells.

\section{Hemolysis of Noninfective RBCs}

After release, the merozoites try to contact the uninfected RBCs to bring its apical end in contact with the RBC membrane. ${ }^{17}$ Soon, they discharge their contents, which include proteases, phospholipases, and lipids. These discharged components induce significant structural changes in the skeletal components of red cell membrane.

Sometimes, the parasite protein released in the plasma may also get deposited over the noninfected erythrocytes. This alters the antigenic and vascular properties of the noninfected RBCs. The infected and noninfected RBCs with altered properties get filtered in the spleen, which could be due to mechanical or inflammatory process.

\section{Splenic and Reticuloendothelial Hyperactivity}

The RBCs thus altered after being infected by merozoites or being deposited by parasitic protein tend to get rejected or removed from the main blood stream when they reach the spleen. There is increased destruction and the removal of infected as well as uninfected erythrocytes, decreased erythrocyte production as well as suppression of the erythropoietic response, all of which are responsible for causing malarial anemia. 


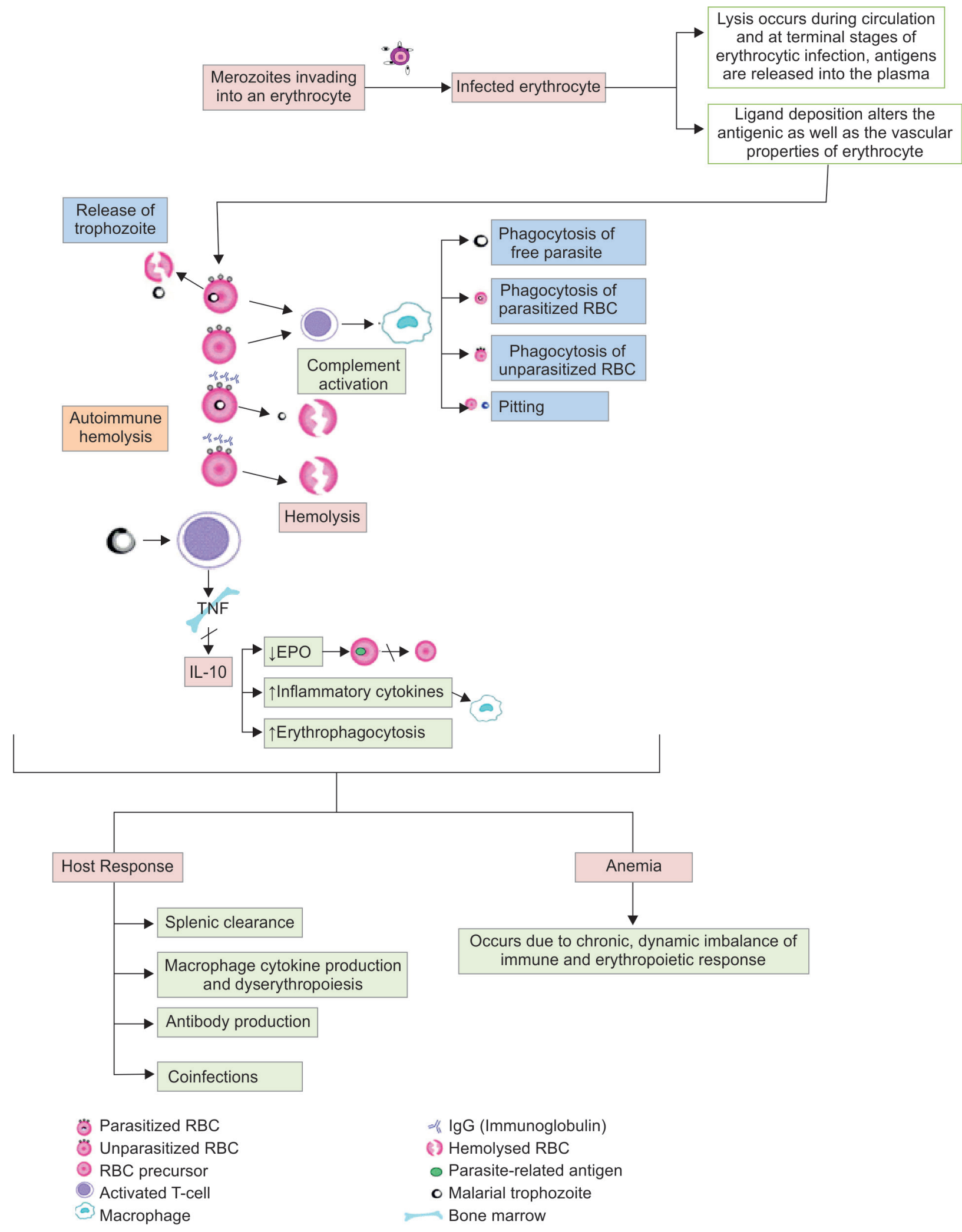

Fig. 3: Pathophysiology of anemia due to malaria. EPO: Erythropoietin

\section{Suppressed Erythropoiesis and Role of Cytokines in Malarial Anemia}

Some emerging evidence has suggested that deficient erythropoietin production is not the actual cause of inadequate erythropoiesis in malaria, ${ }^{21}$ rather this could be due to the involvement of cytokines and various other mediators of inflammation (e.g., hemozoin, a parasite-derived polymerized heme). Cytokines are known to play an important role in the maturation of erythroid cells. ${ }^{22}$ The cytokine interleukin (IL)-6 leads to induction of hepcidin expression, 
which is considered to be a master regulator of iron trafficking. This, in turn, leads to a decline in iron availability for erythropoiesis. Presence of transforming growth factor (TGF) inhibits erythroblast proliferation; tumor necrosis factor (TNF)- $\alpha$ leads to induction of cleavage of major erythroid transcription factor, GATA-1. Other mediators, such as interferon- $\gamma$ (IFN- $\gamma$ ) induce macrophage production of TNF-related apoptosis-inducing ligand (TRAIL). The TRAIL causes inhibition of erythroblast differentiation.

\section{Proinflammatory Mediators}

For a successful type I response to malaria, there is requirement of a proportional and timely managed release of IL-12, IFN- $\gamma$, and TNF- $\alpha$ to minimize parasitemia and preserve the erythropoietic process. ${ }^{23,24}$ The proinflammatory phase is then expected to be followed by a time-based retraction of this response by type II cytokines, such as IL-10, TGF- $\beta$, as well as IL- 4 to avoid any kind of inflammatory host damage. ${ }^{25}$

The pathology in malaria is associated with elevated TNF- $\alpha$ levels and according to its first hypothesis in 1978, it is found to be involved in the reduced host immune response to malaria. Various studies demonstrate a close association between elevated TNF- $\alpha$ levels and increased mortality and morbidity in individuals with malaria. ${ }^{26,27}$ On the contrary, TNF- $\alpha$ is also considered to be critical for parasite killing and prevention of parasite replication. ${ }^{26-30}$ Along with its direct effects, TNF- $\alpha$ induces production of macrophage migration inhibitory factor (MIF) ${ }^{31,32}$ and nitric oxide synthase type II ( $\mathrm{NOS}_{2}$, inducible NOS), which causes direct parasite-killing effects by generating nitric oxide (NO). ${ }^{33}$

Exacerbation of inflammation (by inducing cyclooxygenase- 2 and subsequent generation of effector molecules, like prostaglandins) is also caused by TNF- $\alpha .^{34}$ The TNF- $\alpha$ has also been linked to many of the signs and symptoms associated with malaria, such as fever, nausea, vomiting, diarrhea, anorexia, headache myalgias, and thrombocytopenia. ${ }^{35}$

Although both IFN- $\gamma$ and TNF- $\alpha$ are responsible for protection in adults and children during the early stages of a P. falciparum infection (by stimulating monocyte/ macrophage activation and aiding in controlling parasitemia), ${ }^{36}$ their overproduction is also associated with anemia. ${ }^{37,38}$ A significant contribution to bone marrow suppression, dyserythropoiesis, and erythrophagocytosis as a result of enhanced malarial anemia pathogenesis occurs due to excessive release of mediators IFN- $\gamma$ and TNF- $\alpha$, along with NO. ${ }^{39,40}$

\section{Iron Deficiency and Protection from Malaria}

Iron is found to be the major limiting factor for the growth of many protozoan or bacterial pathogens. Proliferation of Plasmodium requires iron, both during the pre-erythrocytic stage as well as the erythrocytic stage of infection. Malaria itself causes major disturbances in distribution and utilization of iron, through mechanisms, such as hemolysis, release of heme, dyserythropoiesis, deposition of iron in macrophages, and reduced absorption of dietary iron.

In vitro growth of malarial parasite could be, therefore, restricted by the use of iron-chelating agents, such as desferrioxamine. ${ }^{41}$ This has been found in murine models of malaria infection, and also in malaria-infected monkeys. Consequently, iron-chelating agents have been reviewed as an adjunct or primary antimalarial therapy. A better understanding of how Plasmodium parasites acquire iron during their various life stages might help in attaining success in the development of antimalarial drugs that are targeted toward the parasite's access to iron. Deficiency of iron in humans is likely to provide protection against severe malaria. On the contrary, supplementation with iron increases risks of infection and severity of disease. ${ }^{42}$ Concomitant deficiency of iron is usually treated after resolution of parasitemia.

\section{CLINICAL FEATURES OF MALARIAL ANEMIA}

\section{Severe Malarial Anemia}

Severe malaria is linked with the expansion of anemia, typically normochromic and normocytic types, showing a prominent absence of reticulocytes. Nevertheless, in endemic areas, the morphology might be predisposed by the nutritional status of the subject and certain helminthiasis, causing an accompanying microcytic (iron deficiency) and macrocytic (folic acid deficiency) constituent. The contributing mechanisms are multifactorial, together with hemolysis of infected and uninfected RBCs, unsuitable bone marrow response, and frequent other separate factors [e.g., hookworm infestation, glucose-6-phosphate dehydrogenase (G6PD) deficiency, bacteremia, human immunodeficiency virus (HIV), vitamin B12 and vitamin A deficiency]. ${ }^{43}$ In areas of great endemicity, severe anemia is a problematic condition in children, which can sometimes be fatal. ${ }^{44}$ In epidemic relative to endemic areas, severe anemia might also progress in adult population and pregnant women, particularly primiparae. According to the World Health Organization (WHO), severe malarial anemia is well-defined in the presence of a hemoglobin level of higher than $5 \mathrm{gm} / \mathrm{dL}$, or hematocrit value of greater than $15 \% .{ }^{45}$ The UK malaria treatment guidelines define severe anemia when the levels of the hemoglobin are less than $8 \mathrm{gm} / \mathrm{dL} .{ }^{46}$ Pathological significances of anemia are predominantly to such degree of anemia, though they are also prominently related to the quickness at which it grows. In this viewpoint, 
decisions concerning blood transfusion should be taken at an individual level. Children suffering with severe anemia and respiratory distress will have an advantage from transfusions that might be lifesaving. ${ }^{47}$

\section{Hematological Features}

Parasite incursion of red cell arises when the extracellular form of the parasite, the merozoite, is on the loose following rupture of an infected red cell and that ascribes to the surface of an uninfected red cell. In a moderately short period of 30 to 90 seconds, the invasion process is wide ranging. ${ }^{48}$ While the original contact between the merozoite and the red cell is accidental, for positive invasion, the merozoite actively re-orients itself by means of actin-myosin motors, to carry its apical end in connection with the red cell membrane. ${ }^{49} \mathrm{~A}$ junctional zone at the site of apposition is shaped, and particular organelles in the apical end of the polar merozoite, called rhoptries and micronemes, release their contents, which comprises proteases, phospholipases, and lipids. These discharged constituents persuade noteworthy structural changes in the red cell membrane counting with membrane invagination and phosphorylation of membrane skeletal components. A great amount of such parasite proteins have been recognized in the merozoite of $P$. falciparum, counting with EBA175, EBL-1, and EBA-140, for which cognate receptors on red cells are glycophorin $A$, glycophorin $B$, and glycophorin $\mathrm{C}$, correspondingly.

An enormous amount of membrane transporters permit the human red cells to strongly control their cell volume and thus, their state of cell hydration permitting them to uphold cell hemoglobin concentration among narrow limits of 29 to $37 \mathrm{gm} / \mathrm{dL}$ with a mean cell hemoglobin concentration of $33 \mathrm{gm} / \mathrm{dL}$. A significant role for state of red cell hydration in parasite invasion has been recognized. ${ }^{43}$ Dehydration of red cells due to deregulation of membrane transport function subsequently results in a cell hemoglobin concentration of greater than $37 \mathrm{gm} / \mathrm{dL}$. This leads to reduced competence of invasion and at a cell hemoglobin concentration of higher than $41 \mathrm{gm} / \mathrm{dL}$ where the red cells are resilient to invasion. The mechanistic origin for the effect of state of cell dehydration upon the parasite invasion is yet to be elucidated.

Cell dehydration is a feature of red cells in hemoglobinopathies consisting of $\mathrm{HbAS}, \mathrm{HbSS}, \mathrm{HbAC}, \mathrm{HbSC}$, and $\mathrm{HbCC}$, which are extremely prevalent in African countries, as well as in hereditary xerocytosis, a red cell membrane disorder. In these red cell disorders, 5 to $30 \%$ of the red cells have a cell hemoglobin concentration of greater than $37 \mathrm{gm} / \mathrm{dL}$, while in normal individuals, less than $1 \%$ of circulating red cells have a cell hemoglobin concentration of higher than $37 \mathrm{gm} / \mathrm{dL}$. The occurrence
Table 1: RBC variants and protection against malaria

\begin{tabular}{|c|c|}
\hline Red cell abnormality & Mechanism of protection \\
\hline $\begin{array}{l}\text { Glycophorin A variants } \\
\text { or deficiency }\end{array}$ & $\begin{array}{l}\text { Decreased invasion efficiency owing } \\
\text { to changed red cell receptor }\end{array}$ \\
\hline $\begin{array}{l}\text { Glycophorin B variants } \\
\text { or deficiency }\end{array}$ & $\begin{array}{l}\text { Decreased invasion efficiency owing } \\
\text { to changed red cell receptor }\end{array}$ \\
\hline $\begin{array}{l}\text { Glycophorin C variants } \\
\text { or deficiency }\end{array}$ & $\begin{array}{l}\text { Decreased invasion efficiency owing } \\
\text { to changed red cell receptor }\end{array}$ \\
\hline $\begin{array}{l}\text { Hereditary ovalocytosis } \\
\text { due to mutant band } 3\end{array}$ & $\begin{array}{l}\text { Decreased invasion efficiency owing } \\
\text { to changed red cell receptor and/ } \\
\text { or as a consequence of amplified } \\
\text { membrane rigidity }\end{array}$ \\
\hline $\begin{array}{l}\text { Hemoglobinopathies: } \\
\mathrm{HbAS}, \mathrm{HbSS}, \mathrm{HbSC} \\
\mathrm{HbAC} \text {, and } \mathrm{HbCC}\end{array}$ & $\begin{array}{l}\text { Decreased invasion efficiency due } \\
\text { to red cell dehydration and reduced } \\
\text { capability of infected red cells to } \\
\text { attach to the endothelial cells due } \\
\text { to reduced expression of adhesive } \\
\text { ligands on infected red cells }\end{array}$ \\
\hline
\end{tabular}

of such a large fraction of dehydrated red cells in these red cell disorders evidently decreases the threat of development of high degrees of parasitemia and, henceforth, reduces the rigorousness of disease as demonstrated in Table 1.

\section{Black Water Anemia}

Black water fever (BWF) occurs due to massive hemolysis of RBCs in the blood stream with subsequent hemoglobinuria, anemia, and is often accompanied by renal failure. The BWF most often occurs in P. falciparum infections, but it has also been documented in P. vivax, P. malariae, as well as in case of mixed infections. ${ }^{50-55}$ Although the exact mechanisms involved here remain unclear, there are several factors that are found to be associated with BWF, such as G6PD deficiency, severe malarial infection, treatment of malaria with amino-alcohol drugs, mainly quinine, and presence of other bacterial or viral infections. ${ }^{51,52,56}$

It was previously described as a disease to "blanch the cheek of the bravest". Earlier, mortality rate was high (20-30\%). Presently, mortality is much lower. In less severe cases of BWF, passage of black or dark brown or red urine is often not associated with significant renal impairment. It is usually transient, and resolves without complications. In severe cases, acute tubular necrosis develops from massive hemolysis.

\section{Anemia due to $P$. falciparum and $P$. vivax Infection}

Plasmodium falciparum is a protozoan parasite which is responsible for the most virulent form of human malaria. It is responsible for the death of at least one million children annually. The mature RBCs get infected by the 
asexual blood stage parasite of $P$. falciparum, and all these stages of infection are responsible for the majority of all the pathologies and symptoms associated with malaria. Cyclical fevers and chills have been linked to uncomplicated malaria and the periodicity of these factors portrays the intra-erythrocytic cycle. Severe malaria includes conditions or pathologies like lactic acidosis, cerebral malaria (that results from adhesion of infected RBCs with the endothelium present in the brain), and severe anemia. ${ }^{57,58}$ Of all these several pathologies, severe anemia, which is defined by a hemoglobin concentration of less than $5 \mathrm{gm} / \mathrm{dL}$, remains the least understood. However, severe anemia remains a major health problem in endemic areas for pregnant women as well as children, and it is thought to be the main reason behind malarial infant mortality. ${ }^{59}$ Inadequate response to anemia also plays a significant role, in addition to destruction of the infected and uninfected RBCs.

Plasmodium vivax, which is at large a nonlethal malaria, also causes anemia that could be severe. Few preventative strategies are present in this case. Blood transfusion can manage severe malarial anemia, but it also carries the risk of HIV and other blood-borne infections in endemic areas. $^{3}$

\section{TREATMENT OF ANEMIA DUE TO MALARIA}

\section{Blood Transfusion}

Various options are available for the treatment of anemia due to malarial infection. Blood transfusion is usually indicated in high-transmission settings where hemoglobin level is less than $5 \mathrm{gm} / \mathrm{dL}$ (hematocrit $<15 \%$ ) or in low-transmission settings, where hemoglobin level is less than $7 \mathrm{gm} / \mathrm{dL}$ (hematocrit $<20 \%$ ). To prevent volume overload, blood transfusion containing $10 \mathrm{~mL} / \mathrm{kg}$ of packed cells administered over a period of 2 to 4 hours along with the diuretic therapy is usually recommended. ${ }^{60}$ For patients with hypovolemia, whole blood transfusion might be suggested. There is a cumulative affinity in the direction of whole blood transfusion built on the confirmation that numerous patients suffering from malarial anemia are really hypovolemic, having increased blood pressure, low central venous pressure, and delayed capillary refill time. ${ }^{61}$

Centered on these consequences, the institute of thought hypothesizes that a problem in cardiac system does not take place and the type of shock in malarial anemia closely resembles compensated hypovolemic type. ${ }^{62}$ Thus, most clinicians advocate initial expansion in volume and whole blood transfusion for improving tissue perfusion and acidosis. ${ }^{63}$

Unadorned malarial conditions are related to about $6.5 \%$ decrease in total volume of the body water, a loss somewhat greater than mild dehydration such that expansion in the overzealous volume possibly will be harmful. ${ }^{64}$ While the blood transfusion is performed, there might be chances of instant and extensive difficulties that are considered contrary to their possible advantages. Such type of threats includes transmission of blood-borne infections, such as cytomegalovirus, hepatitis, pathogens present in blood (screened and unscreened), Ebstein-Barr virus, HIV, etc. ${ }^{65,66} \mathrm{~A}$ number of researches have shown that the intention of increasing the threshold value for blood transfusion in case of malarial anemia is to restrict the blood transfusion for those individuals who are at the threat of death in the favor of conservative management, comprising effective antimalarial agents for other individuals having not so severe malarial infection. ${ }^{67,68}$ A recent Cochrane review has revealed insufficient evidence to determine whether the practice of giving routine blood transfusion to clinically stable children with severe anemia is likely to bring about an improvement in the mortality rates or measurement of hematocrit levels. ${ }^{68}$

\section{Antimalarial Therapy}

In cases of anemia, antimalarial therapy needs to be initiated to eradicate the malarial infection. There are two major classes of drugs that are used for parenteral treatment of severe malaria. These include artemisinin derivatives (artesunate and artemether) and the cinchona alkaloids (quinine and quinidine). ${ }^{69}$ Once the patients have received parenteral therapy for at least 24 hours and are able to tolerate oral medication, they may be switched over to an oral regimen until completion of therapy.

Before being referred to an acute care facility, patients with severe malaria should be treated with a prereferral dose of intramuscular or rectal artemisinin derivatives in areas where they cannot be immediately commenced on intravenous (IV) therapy, but artemisinin derivatives are readily available. Usually, a single dose of intramuscular artesunate is preferred. Children weighing less than $20 \mathrm{~kg}$ are administered artesunate in a dosage of $3 \mathrm{mg} / \mathrm{kg}$ body weight. For children more than $20 \mathrm{~kg}$ in weight and adults, artesunate is administered in a dosage of $2.4 \mathrm{mg} / \mathrm{kg}$ body weight. ${ }^{69}$

Results of an open, randomized controlled trial in Malawian children with cerebral anemia have shown that treatment with intramuscular artemether in comparison with IV quinine is not likely to confer a survival advantage among children with life-threatening cerebral malaria. ${ }^{70}$ In a Nigerian study, intramuscular artemether was compared with intramuscular sulfadoxinepyrimethamine in children with moderately severe malaria requiring parenteral therapy. ${ }^{71}$ Administration of artemether produced significantly shorter parasite and 
fever clearance times, but a higher parasite recrudescence rate in comparison with intramuscular sulfadoxinepyrimethamine. No significant difference was, however, found in their initial parasitological cure rates. In an open, randomized controlled clinical trial in Sudan, intramuscular artemether was compared with IV quinine in children with severe falciparum malaria. ${ }^{72}$ There was no significant difference between the two drugs regarding parasite and fever clearance times, as well as the parasite recrudescence rate. The results of these studies show that artemether can be considered as a potentially useful drug for treatment of moderate and severe malaria. However, further evidence in the form of well-designed randomized controlled trials is required to define the role of artemether in cases of malarial anemia.

\section{COMPLICATIONS}

Jaundice is the most common problem in malarial anemia. Most frequently, it is triggered by hemolysis and consequently there is an increase in the levels of unconjugated bilirubin in the blood. Hemolysis can also upraise levels of the hepatic enzyme, aspartate aminotransferase. These conclusions alone, therefore, do not suggest simple hepatic dysfunction in cases of malaria. ${ }^{73}$ The mild boost in serum bilirubin level typically returns to normal within 3 to 5 days of operative antimalarial treatment. It does not necessitate any superior dietary limitations nor does it require any management by "traditional methods" (Ayurveda, alternative therapies, etc.). Nevertheless, hepatic dysfunction may also be realized in circumstances of unadorned falciparum malaria. Such patients have conjugated hyperbilirubinemia, clear elevations of aspartate aminotransferase and alanine aminotransferase, and extension of prothrombin time. ${ }^{62}$

Massive hemolysis, disseminated intravascular coagulation, and hepatic dysfunction possibly contribute to this malaria-associated hepatic dysfunction. Clinical signs of liver failure are at no time due to malaria and in such circumstances, other related hepatic diseases, like viral hepatitis, should be deliberated. Serum bilirubin and serum transaminases assessment should be done in all cases of falciparum malaria, who have icterus and pallor and who are sick and necessitate admission. ${ }^{73}$ Prothrombin time and serum protein estimation might also be required. In majority of the patients, the bilirubin and enzyme levels return to normal within days of antimalarial treatment. No other particular treatment is required.

\section{EFFECT OF MALARIA IN PREGNANCY}

In pregnancy, the adverse effects of malaria infection that result from the systemic infection are comparable with the effects of any severe febrile illness in pregnancy.
This can be associated with increased maternal and fetal mortality, miscarriage, stillbirth, and premature birth. Malarial infection causes placental reaction by clogging the placental intervillous spaces with plasmodiuminfected RBCs, and macrophages, especially during the second half of pregnancy. As a result, the malaria-infected placenta is unable to carry out its main function, i.e. provision of nutrients to the fetus. In a normal woman, the transplacental passive immunity, due to the passage of immunoglobulin $\mathrm{G}$ through the placenta, helps in protecting the newborns against infection. This immunity is also deficient in fetuses of a malaria-infected woman.

\section{Clinical Presentation}

There are no specific symptoms or signs associated with malarial infection, and the patient may present with a flulike illness. A pregnant woman with pyrexia of unknown origin should be enquired about history of travel to a malaria-endemic area. Severity of malaria in the pregnant woman should be assessed and documented in the patient's clinical notes because this is likely to help in its management. The severity of malaria helps in determining the course of treatment and predicting the case fatality rate.

Uncomplicated malaria in the United Kingdom is defined as presence of fewer than $2 \%$ parasitized RBCs in a woman with no signs of severity or presence of any complicating features. Complicated malaria, on the contrary, is defined as the presence of $2 \%$ or more parasitized red blood. Case fatality rates are low, approximately $0.1 \%$ in uncomplicated cases of malaria. In cases of severe malaria during pregnancy, fatality rates can be as high as $50 \% .{ }^{74}$ Clinical features encountered in cases of severe or complicated malaria in adults are listed in Table $2 .^{74}$

\section{Investigations}

Blood film: In case of clinical suspicion of malaria, diagnosis must be confirmed by performing the microscopic

Table 2: Clinical presentation in case of severe or complicated malaria in adults

\footnotetext{
- Prostration

- Impaired consciousness

- Respiratory distress (acidotic breathing, acute respiratory distress syndrome $)^{*}$

- Pulmonary edema (including radiological evidence) ${ }^{\star}$

- Multiple convulsions

- Circulatory collapse, shock (blood pressure <90/60 mm Hg)

- Abnormal bleeding, disseminated intravascular coagulation

- Jaundice

- Hemoglobinuria (without G6PD deficiency)
}

${ }^{*}$ Common features in pregnant women with severe or complicated malaria 
Table 3: Laboratory findings in cases of severe or complicated malaria in adults

- Severe anemia (hemoglobin $<8.0 \mathrm{gm} / \mathrm{dL}$ )

- Thrombocytopenia

- Hypoglycemia $(<2.2 \mathrm{mmol} / \mathrm{L})^{*}$

- Acidosis $(\mathrm{pH}<7.3)$

- Renal impairment (oliguria $<0.4 \mathrm{~mL} / \mathrm{kg}$ body weight/hour or creatinine $>265 \mathrm{mmol} / \mathrm{L})$

- Hyperlactatemia (correlates with mortality)

- Hyperparasitemia (>2\% parasitized RBCs)

- "Algid malaria"-Gram-negative septicemia*

- Lumbar puncture to exclude meningitis

${ }^{*}$ Common features in pregnant women with severe or complicated malaria

examination of thick and thin blood films for parasites. Other laboratory investigations, which may be required in severe cases of malaria, are listed in Table 3.

\section{Management}

Malaria during pregnancy must be managed as an emergency situation, preferably by a multidisciplinary team comprising an intensive care specialist, infectious disease specialist, obstetrician, neonatologist, etc. Women, who are recovering from an episode of malaria during pregnancy, are advised to have regular absolute neutrophil count, including assessment of maternal hemoglobin, platelet and glucose levels, and fetal growth scans.

Treatment of choice for severe falciparum malaria is IV artesunate. The IV quinine may be used, if artesunate is not available. Blood films must be monitored at every 24 hourly intervals. However, the blood film must be repeated in case of clinical deterioration. Patient's hospitalization is important for ensuring compliance to therapy. The 7-day course of quinine may be associated with significant adverse effects, principally cinchonism, which may include signs and symptoms, such as tinnitus, headache, nausea, diarrhea, altered auditory acuity, and blurred vision. This may be frequently a cause of noncompliance, which may eventually result in the failure of therapy. ${ }^{74-78}$

Uncomplicated P. falciparum (or mixed infections, such as P. falciparum and P. vivax) can be treated with drugs, such as quinine and clindamycin. Chloroquine can be used for treating infection with P. vivax, P. ovale, or P. malariae. Primaquine should not be preferably used during pregnancy. The clinician should switch to IV therapy in cases of persistent vomiting.

Antipyretics (paracetamol in standard doses) must be used for the treatment of fever. Prompt treatment of fever in malaria is necessary because it has been found to be associated with complications, such as premature labor and fetal distress. Paracetamol should be prescribed in the dosage of 1 gm every 4 to 6 hours (to a maximum of $4 \mathrm{gm} /$ day). Women with malaria must be screened for anemia and treated appropriately.

Women should be advised about the risk of recurrence of malaria, and a suitable follow-up plan must be devised. This may involve repeating the blood film in case the symptoms or fever returns. Infections, which recur following treatment, are likely to be intrinsically less sensitive to the drugs that have been previously used against them. The options for treatment of recurrent infection in pregnancy in the United Kingdom are limited. However, if quinine and clindamycin have failed as first-line treatment, an alternative should be considered. Atovaquone-proguanil artesunate and dihydroartemisinin-piperaquine have been effectively used in pregnant women with multiple recurrent infections. ${ }^{79}$ The WHO has recommended a 7-day regimen of artesunate in the dosage of $2 \mathrm{mg} / \mathrm{kg} /$ day or $100 \mathrm{mg}$ daily for 7 days and clindamycin in the dosage $450 \mathrm{mg}$ three times daily for 7 days. The general rule of thumb is that the consequences of malaria are more harmful to the woman and her baby in comparison with the side effects related to the use of antimalarial medications.

\section{INTRAPARTUM PERIOD}

In cases of severe malaria, particularly in presence of fever, cardiotocograph monitoring during labor is required. Electronic fetal monitoring may reveal abnormalities, such as fetal tachycardia, bradycardia, or late decelerations. In cases where the woman is being administered quinine, it is important to exclude maternal hypoglycemia as the cause of fetal distress. Management of fetal distress is similar to that in normal obstetric cases. A pediatrician must be alerted well in advance in these cases. Tocolytic therapy and prophylactic steroid therapy can be administered in the usual obstetric doses provided there are no obstetric contraindications. Uncomplicated malaria in pregnancy per se is not an indication for induction of labor.

The woman must be informed about the risk of vertical transmission of malarial infection. Vertical transmission of malaria takes place when malarial parasites cross the placenta, either during pregnancy or at the time of birth. Vertical transmission to the fetus can occur, particularly when there is infection at the time of birth, and the placenta and cord are blood film positive for malaria.

In cases of peripartum malaria, at the time of baby's birth, placental specimen must be sent for histopathological examination. Blood films from the cord and baby's blood must be investigated to detect congenital malaria at an early stage. Though the presence of positive 
placental blood films and fever in the infant is indicative of congenital malaria, a blood film from the baby is required for confirmation. All neonates, whose mothers developed malaria in pregnancy, should be screened for malaria with standard microscopy of thick and thin blood films at birth. Blood films should be then taken at weekly intervals for 28 days.

\section{Complications}

\section{Maternal Complications}

Malarial infection during pregnancy can have numerous adverse effects on both mother and fetus, ${ }^{80-82}$ including general decline in immunity, maternal anemia (due to increased hemolysis and sequestration of infected RBCs into the reticuloendothelial system), miscarriage, stillbirths, intrauterine death, premature delivery, intrauterine growth restriction, and delivery of low birthweight infants ( $<2500$ gm or $<5.5$ pounds), fetal heart rate abnormalities, pulmonary edema, acute respiratory distress syndrome, hypoglycemia, severe anemia, secondary bacterial infection, principally Gram-negative septicemia, etc. Secondary bacterial infection should be suspected if the patient becomes hypotensive. These complications are likely to result in an overall increase in maternal and fetal mortality and morbidity. Another problem related to the presence of malarial infection in pregnancy is the widespread concerns regarding the safety of various medications used for treatment and prophylaxis.

\section{Congenital Malaria}

Congenital malaria in the very young infant or newborn results from the passage of parasites or the infected RBCs from the mother to the newborn while in utero or during delivery.

\section{CONCLUSION}

Anemia is a common problem occurring in cases of malarial infection, although the consequences are more pronounced with P. falciparum malaria. Malarial anemia is a cause of significant morbidity and mortality, especially among children and pregnant women. Malarial anemia is caused by various pathophysiologic mechanisms and its etiology largely remains multifactorial. In areas where malaria infection is endemic, comorbidities like other parasitic infestations, iron, folate and vitamin B12 deficiency, deficiency of other nutrients, etc., can contribute to the development of anemia in cases with malarial infection. Jaundice is the most common complication to take place in case of malarial anemia. Blood transfusion may be required in moderate-to-severe cases. Concomitant deficiency of iron is usually treated after resolution of parasitemia.

\section{REFERENCES}

1. WHO. World malaria report. Geneva: World Health Organization Publication; 2015.

2. Achidi EA, Apinjoh TO, Anchang-Kimbi JK, Mugri RN, Ngwai AN, Yafi CN. Severe and uncomplicated falciparum malaria in children from three regions and three ethnic groups in Cameroon: prospective study. Malar J 2012 Jun;11:215.

3. Nkuo-Akenji TK, Chi PC, Cho JF, Ndamukong KK, Sumbele I. Malaria and helminth co-infection in children living in a malaria endemic setting of mount Cameroon and predictors of anemia. J Parasitol 2006 Dec;92(6):1191-1195.

4. Sumbele IU, Samje M, Nkuo-Akenji T. A longitudinal study on anaemia in children with Plasmodium falciparum infection in the Mount Cameroon region: prevalence, risk factors and perceptions by caregivers. BMC Infect Dis 2013 Mar;13:123.

5. van Hensbroek MB, Jonker F, Bates I. Severe acquired anaemia in Africa: new concepts. Br J Haematol 2011 Sep;154(6): 690-695.

6. Price RN, Simpson JA, Nosten F, Luxemburger C, Hkirjaroen L, ter Kuile F, Chongsuphajaisiddhi T, White NJ. Factors contributing to anemia after uncomplicated falciparum malaria. Am J Trop Med Hyg 2001 Nov;65(5):614-622.

7. Buffet PA, Safeukui I, Milon G, Mercereau-Puijalon O, David PH. Retention of erythrocytes in the spleen: a doubleedged process in human malaria. Curr Opin Hematol 2009 May;16(3):157-164.

8. Phillips RE, Looareesuwan S, Warrell DA, Lee SH, Karbwang J, Warrell MJ, White NJ, Swasdichai C, Weatherall DJ. The importance of anaemia in cerebral and uncomplicated falciparum malaria: role of complications, dyserythropoiesis and iron sequestration. Q J Med 1986 Mar;58(227):305-323.

9. Guerra CA, Howes RE, Patil AP, Gething PW, Van Boeckel TP, Temperley WH, Kabaria CW, Tatem AJ, Manh BH, Elyazar IR, et al. The international limits and population at risk of Plasmodium vivax transmission in 2009. PLoS Negl Trop Dis 2010 Aug;4(8):e774.

10. Carter R, Mendis KN. Evolutionary and historical aspects of the burden of malaria. Clin Microbiol Rev 2002 Oct;15(4): 564-594.

11. Galinski MR, Barnwell JW. Plasmodium vivax: who cares? Malar J 2008 Dec;7(Suppl 1):S9.

12. Price RN, Tjitra E, Guerra CA, Yeung S, White NJ, Anstey NM. Vivax malaria: neglected and not benign. Am J Trop Med Hyg 2007 Dec;77(6 Suppl):79-87.

13. Douglas NM, Anstey NM, Angus BJ, Nosten F, Price RN. Artemisinin combination therapy for vivax malaria. Lancet Infect Dis 2010 Jun;10(6):405-416.

14. Rosenberg R. Plasmodium vivax in Africa: hidden in plain sight? Trends Parasitol 2007 May;23(5):193-196.

15. Mendis K, Sina BJ, Marchesini P, Carter R. The neglected burden of Plasmodium vivax malaria. Am J Trop Med Hyg 2001 Jan-Feb;64(1-2 Suppl):97-106.

16. Guerra CA, Snow RW, Hay SI. Mapping the global extent of malaria in 2005. Trends Parasitol 2006 Aug;22(8):353-358.

17. McKenzie FE, Jeffery GM, Collins WE. Plasmodium vivax blood-stage dynamics. J Parasitol 2002 Jun;88(3):521-535.

18. WHO. World malaria report. Geneva: WHO; 2011. [cited 2017 Nov]. Available from: http://www.who.int/malaria/ world_malaria_report_2011/9789241564403_eng.pdf.

19. Hay SI, Guerra CA, Tatem AJ, Noor AM, Snow RW. The global distribution and population at risk of malaria: past, present, and future. Lancet Infect Dis 2004 Jun;4(6):327-336. 
20. Hay SI, Smitha DL, Snow RW. Measuring malaria endemicity from intense to interrupted transmission. Lancet Infect Dis 2008 Jun;8(6):369-378.

21. Chang KH, Stevenson MM. Malarial anaemia: mechanisms and implications of insufficient erythropoiesis during bloodstage malaria. Int J Parasitol 2004 Dec;34(13-14):1501-1516.

22. Chasis JA, Mohandas N. Erythroblastic islands: niches for erythropoiesis. Blood 2008 Aug;112(3):470-478.

23. Crutcher JM, Stevenson MM, Sedegah M, Hoffman SL. Interleukin-12 and malaria. Res Immunol 1995 Sep-Oct;146(7-8): 552-559.

24. Stevenson MM, Tam MF, Wolf SF, Sher A. IL-12-induced protection against blood-stage Plasmodium chabaudi AS requires IFN-gamma and TNF-alpha and occurs via a nitric oxidedependent mechanism. Immunol J 1995 Sep;155(5):2545-2556.

25. Clark IA, Budd AC, Alleva LM, Cowden WB. Human malarial disease: a consequence of inflammatory cytokine release. Malar J 2006 Oct;5:85.

26. Grau GE, Taylor TE, Molyneux ME, Wirima JJ, Vassalli P, Hommel M, Lambert PH. Tumor necrosis factor and disease severity in children with falciparum malaria. N Engl Med J 1989 Jun;320(24):1586-1591.

27. Kwiatkowski D, Hill AV, Sambou I, Twumasi P, Castracane J, Manogue KR, Cerami A, Brewster DR, Greenwood BM. TNF concentration in fatal cerebral, non-fatal cerebral, and uncomplicated Plasmodium falciparum malaria. Lancet 1990 Nov;336(8725):1201-1204.

28. Kern P, Hemmer CJ, Van Damme J, Gruss HJ, Dietrich M. Elevated tumor necrosis factor alpha and interleukin-6 serum levels as markers for complicated Plasmodium falciparum malaria. Am Med J 1989 Aug;87(2):139-143.

29. Kwiatkowski D, Cannon JG, Manogue KR, Cerami A, Dinarello CA, Greenwood BM. Tumour necrosis factor production in Falciparum malaria and its association with schizont rupture. Clin Exp Immunol 1989 Sep;77(3):361-366.

30. Clark IA, Ilschner S, MacMicking JD, Cowden WB. TNF and Plasmodium berghei ANKA-induced cerebral malaria. Immunol Lett 1990 Aug;25(1-3):195-198.

31. Calandra T, Bucala R. Macrophage migration inhibitory factor: a counter-regulator of glucocorticoid action and critical mediator of septic shock. Inflamm J 1995-1996;47(1-2):39-51.

32. Lan HY, Yang N, Metz C, Mu W, Song Q, Nikolic-Paterson DJ, Bacher M, Bucala R, Atkins RC. TNF-alpha up-regulates renal MIF expression in rat crescentic glomerulonephritis. Mol Med 1997 Feb;3(2):136-144.

33. Rockett K, Awburn MM, Cowden WB, Clark IA. Killing of Plasmodium falciparum in vitro by nitric oxide derivatives. Infect Immun 1991 Sep;59(9):3280-3283.

34. Perkins DJ, Kniss DA. Tumor necrosis factor-alpha promotes sustained cyclooxygenase-2 expression: attenuation by dexamethasone and NSAIDs. Prostaglandins 1997 Oct;54(4): 727-743.

35. Schwartz JE, Scuderi P, Wiggins C, Rudolph A, Hersh EM. A phase I trial of recombinant tumor necrosis factor (rTNF) administered by continuous intravenous infusion in patients with disseminated malignancy. Biotherapy 1989 Sep;1(3): 207-214.

36. Kremsner PG, Winkler S, Brandts C, Wildling E, Jenne L, Graninger W, Prada J, Bienzle U, Juillard P, Grau GE. Prediction of accelerated cure in Plasmodium falciparum malaria by the elevated capacity of tumor necrosis factor production. Am J Trop Med Hyg 1995 Nov;53(5):532-538.
37. Lyke KE, Burges R, Cissoko Y, Sangare L, Dao M, Diarra I, Kone A, Harley R, Plowe CV, Doumbo OK, et al. Serum levels of the proinflammatory cytokines interleukin-1 beta (IL-1beta), IL-6, IL-8, IL-10, tumor necrosis factor alpha, and IL-12(p70) in Malian children with severe Plasmodium falciparum malaria and matched uncomplicated malaria or healthy controls. Infect Immun 2004 Oct;72(10):5630-5637.

38. Perkins DJ, Weinberg JB, Kremsner PG. Reduced interleukin-12 and transforming growth factor-beta1 in severe childhood malaria: relationship of cytokine balance with disease severity. J Infect Dis 2000 Sep;182(3):988-992.

39. Biemba G, Gordeuk VR, Thuma PE, Mabeza GF, Weiss G. Prolonged macrophage activation and persistent anaemia in children with complicated malaria. Trop Med Int Health 1998 Jan;3(1):60-65.

40. Clark IA, Cowden WB. The pathophysiology of falciparum malaria. Pharmacol Ther 2003 Aug;99(2):221-260.

41. Mabeza G, Loyevsky M, Gordeuk VR, Weiss G. Iron chelation therapy for malaria: a review. Pharmacol Ther 1999 Jan;81(1):53-75.

42. Spottiswoode N, Duffy PE, Drakesmith H. Iron, anemia and hepcidin in malaria. Front Pharmacol 2014 May;5:125.

43. Bannister L, Mitchell G. The ins, outs and roundabouts of malaria. Trends Parasitol 2003 May;19(5):209-213.

44. Calis JC, Phiri KS, Faragher EB, Brabin BJ, Bates I, Cuevas LE, de Haan RJ, Phiri AI, Malange P, Khoka M, et al. Severe anemia in Malawian children. N Engl J Med 2008 Feb;358(9):888-899.

45. Paslov, G.; Abdalla, S. Anemia. In: Guerrant RL, Walker DH, Weller PF, editors. Tropical infectious diseases: principles, pathogens, and practice. Philadelphia (PA): Churchill Livingstone; 1999. pp. 1551-1564.

46. World Health Organization. Guidelines for the treatment of malaria. 2nd ed. Geneva: World Health Organization; 2010.

47. Lalloo DG, Shingadia D, Pasvol G, Chiodini PL, Whitty CJ, Beeching NJ, Hill DR, Warrell DA, Bannister BA; HPA Advisory Committee on Malaria Prevention in UK Travellers. UK malaria treatment guidelines. J Infect 2007 Feb;54(2): 111-121.

48. Taylor, TE.; Strickland, GT. Malaria. In: Hunter GW, Strickland GT, editors. Hunter's tropical medicine and emerging infectious diseases. 8th ed. Philadelphia (PA): Saunders; 2000. pp. 614-643.

49. Gilson PR, Crabb BS. Morphology and kinetics of the three distinct phases of red blood cell invasion by Plasmodium falciparum merozoites. Int J Parasitol 2009 Jan;39(1):91-96.

50. Tiffert T, Lew VL, Ginsburg H, Krugliak M, Croisille L, Mohandas N. The hydration state of human red blood cells and their susceptibility to invasion by Plasmodium falciparum. Blood 2005 Jun;105(12):4853-4860.

51. Tran TH, Day NP, Ly VC, Nguyen TH, Pham PL, Nguyen HP, Bethell DB, Dihn XS, Tran TH, White NJ. Blackwater fever in southern Vietnam: a prospective descriptive study of 50 cases. Clin Infect Dis 1996 Dec;23(6):1274-1281.

52. Van den Ende J, Coppens G, Verstraeten T, Van Haegenborgh T, Depraetere K, Van Gompel A, Van den Enden E, Clerinx J, Colebunders R, Peetermans WE, et al. Recurrence of blackwater fever: triggering of relapses by different antimalarials. Trop Med Int Health 1998 Aug;3(8):632-639.

53. Rogier C, Imbert P, Tall A, Sokhna C, Spiegel A, Trape JF. Epidemiological and clinical aspects of blackwater fever among African children suffering frequent malaria attacks. Trans R Soc Trop Med Hyg 2003 Mar-Apr;97(2):193-197. 
54. Bruneel F, Gachot B, Wolff M, Régnier B, Danis M, Vachon F; Corresponding Group. Resurgence of blackwater fever in long-term European expatriates in Africa: report of 21 cases and review. Clin Infect Dis $2001 \mathrm{Apr} ; 32(8): 1133-1140$.

55. Dondorp AM, Fanello CI, Hendriksen ICE, Gomes E, Seni A, Chhaganlal KD, Bojang K, Olaosebikan R, Anunobi N, Maitland $\mathrm{K}$, et al. Artesunate versus quinine in the treatment of severe falciparum malaria in African children (AQUAMAT): an open-label, randomised trial. Lancet 2010 Nov;376(9753):1647-1657.

56. Pasvol G. The treatment of complicated and severe malaria. Br Med Bull 2006 Feb;75-76:29-47.

57. Weatherall DJ, Miller LH, Baruch DI, Marsh K, Doumbo OK, Casals-Pascual C, Roberts DJ. Malaria and the red cell. Hematology Am Soc Hematol Educ Program 2002;35-57.

58. Lamikanra AA, Brown D, Potocnik A, Casals-Pascual C, Langhorne J, Roberts DJ. Malarial anemia: of mice and men. Blood 2007 Jul;110(1):18-28.

59. Ekvall H. Malaria and anemia. Curr Opin Hematol 2003 Mar;10(2):108-114.

60. Newton CR, Marsh K, Peshu N, Mwangi I. Blood transfusion For severe anaemia in African children. Lancet 1992 Oct;340(8824):917-918.

61. Maitland K, Pamba A, Newton CR, Levin M. Response to volume resuscitation in children with severe anaemia. Paedtr Crit Care Med 2003 Oct;4(4):426-431.

62. World Health Organization. Severe falciparum malaria. Trans Roy Soc Trop Med Hyg 2000 Apr;94(Suppl 1):S1-S90.

63. Planche T, Onanga M, Schwnk A, Dzeing A, Borrmann S, Faucher JF, Wright A, Bluck L, Ward L, Kombila M, et al. Assessment of volume depletion in children with malaria. PLoS Med 2004 Oct;1(1):e18-e20.

64. Halim NK, Offor E, Ajayi OI. Epidemiological study of seroprevalence of Hepatitis B surface antigen and HIV 1 in blood donors. Niger J Clin Pract 1999;2:42-45.

65. Anderson KC, Weinstein HJ. Transfusion associated graft vs host disease. N Eng J Med 1990 Aug;323(5):315-321.

66. Holzer B, Egger M, Teuscher T, Koch S, Mboya DM, Smith GD. Childhood anaemia in Africa: to transfuse or not transfuse. Acta Trop 1993 Oct;5(1-2):47-51.

67. Bojang KA, Palmer A, Boele van Hensbroek M, Banya WA, Greenwood BM. Management of severe malarial anaemia in Gambian children. Trans R Soc Trop Med Hyg 1997 SepOct;91(5):557-561.

68. Meremikwu M, Smith HJ. Blood transfusion for treating malarial anaemia. Cochrane Database Syst Rev 2000;2:CD001475.

69. World Health Organization. Guidelines for the treatment of malaria. 3rd ed. Geneva: WHO; 2015. [cited 2017 Nov]. Available from: http:/ / www.who.int/malaria/publications / atoz/9789241549127/en/.
70. Taylor TE, Willis BA, Courval JK, Molyneux ME, Molyneux ME. Intramuscular artemether vs intravenous quinine: an open randomized trial in Malawian children with cerebral malaria. Trop Med Int Health 1998 Jan;3(1):3-8.

71. Salako LA, Walker O, Sowunmi A, Omokhodion SJ, Adio R, Oduola AM. Artemether in moderately severe and cerebral malaria in Nigerian children. Trans R Soc Trop Med Hyg 1994 Jun;88(Suppl 1):S13-S15.

72. Adam I, Idris HM, Mohamed-Ali AA, Aelbasit IA, Elbashir MI. Comparison of intramuscular artemether and intravenous quinine in the treatment of Sudanese children with severe falciparum malaria. East Afr Med J 2002 Dec;79(12):621-625.

73. Trampuz A, Jereb M, Muzlovic I, Prabhu RM. Clinical review: severe malaria. Crit Care 2003 Aug;7(4):315-323.

74. Nosten F, McGready R, d'Alessandro U, Bonell A, Verhoeff F, Menendez C, Mutabingwa T, Brabin B. Antimalarial drugs in pregnancy: a review. Curr Drug Saf 2006 Jan;1(1):1-15.

75. Dilling JW, Gemmell AA. A preliminary investigation of fetal deaths following quinine induction. J Obstet Gynecol 1929 Jun;36(2):352-366

76. van Vugt M, Leonardi E, Phaipun L, Slight T, Thway KL, McGready R, Brockman A, Villegas L, Looareesuwan S, White NJ, et al. Treatment of uncomplicated multidrug resistant falciparum malaria with artesunate-atovaquoneproguanil. Clin Infect Dis 2002 Dec;35(12):1498-1504.

77. Royal College of Obstetricians and Gynaecologists. Preventing malaria in pregnancy. Green-top Guideline No. 54A. London: RCOG; 2010.

78. Tarning J, McGready R, Lindegardh N, Ashley EA, Pimanpanarak M, Kamanikom B, Annerberg A, Day NP, Stepniewska K, Singhasivanon P, et al. Population pharmacokinetics of lumefantrine in pregnant women treated with artemether-lumefantrine for uncomplicated Plasmodium falciparum malaria. Antimicrob Agents Chemother 2009 Sep;53(9):3837-3846.

79. Novartis Pharmaceuticals UK Ltd. Riamet $20 / 120$ mg tablets. Summary of Product Characteristics. Electronic Medicines Compendium. England: Novartis Pharmaceuticals UK Ltd; 2009. [cited 2016 Nov]. Available from: www.emc.medicines. org.uk/medicine/9196/SPC/Riamet+20+120mg+tablets / \#pregnancy.

80. Royal College of Obstetricians and Gynaecologists. The diagnosis and treatment of malaria in pregnancy. Greentop Guideline No. 54B. London: RCOG; 2010.

81. Meira DA. Plasmodium falciparum infection and pregnancy. Case reports. Rev Soc Bras Med Trop 1989 Apr-Jun;22(2):99-101.

82. Bounyasong S. Randomized trial of artesunate and mefloquine in comparison with quinine sulfate to treat P. falciparum malaria pregnant women. J Med Assoc Thai 2001 Sep;84(9):1289-1289. 